\title{
Synthesis of SAPO-34 Using Different Combinations of Organic Structure-Directing Agents
}

\author{
Tuan Doan $\left(\mathbb{D}\right.$, Khang Nguyen $\left(\mathbb{D}\right.$, Phong Dam $\mathbb{D}^{\mathbb{D}}$, Thanh Huyen Vuong, Minh Thang Le $\mathbb{D}$, \\ and Huyen Pham Thanh
}

School of Chemical Engineering, Hanoi University of Science and Technology, Hanoi, Vietnam

Correspondence should be addressed to Huyen Pham Thanh; huyen.phamthanh@hust.edu.vn

Received 14 March 2019; Revised 13 May 2019; Accepted 4 July 2019; Published 22 July 2019

Guest Editor: Thanh-Dong Pham

Copyright (C) 2019 Tuan Doan et al. This is an open access article distributed under the Creative Commons Attribution License, which permits unrestricted use, distribution, and reproduction in any medium, provided the original work is properly cited.

\begin{abstract}
The effects of different mixtures of organic structure-directing agents (OSDAs) on the formation of SAPO-34 structure have been investigated. Different OSDAs, namely, triethylamine (TEA), tetraethylammonium hydroxide (TEAOH), and morpholine (Mor) and their combinations were used to synthesize SAPO-34 by a hydrothermal method. The template concentration was optimized by eliminating the competing phases to obtain the purest form of SAPO-34 phase. The as-synthesized samples were analyzed by XRD, FE-SEM/EDS, FT-IR, surface area/pore volume measurements, NH3-TPD, TG/DTA, and 29Si NMR MAS. The selection of template notably impacts the crystal size and physicochemical characteristics of as-synthesized SAPO-34. The sample prepared with 3 Mor:3 TEA:1 TEAOH exhibited the highest total acidity, smallest crystal size below $3 \mu \mathrm{m}$, and high surface area up to $697 \mathrm{~m}^{2} / \mathrm{g}$.
\end{abstract}

\section{Introduction}

Silicoaluminophosphate (SAPO) is a related grade of microporous material applied mostly in the scope of catalysis of processes such as hydro-isomerization of $n$-hexane, gas separations, methanol conversion to light olefins (MTO), pyrolysis reaction, or removal of $\mathrm{NO}_{x}$ by selective catalytic reduction with ammonia $\left(\mathrm{NH}_{3}-\mathrm{SCR}\right)$. SAPO-34 is such an exciting catalyst in the SAPO generation. Since being discovered in the 1980s, large chabazite (CHA) with small channel systems, eight-membered rings $(3.8 \AA \times 3.8 \AA)$, and $9.4 \AA$ in diameter cage called SAPO- 34 has received significant attention, thanks to its high selectivity to light gases separation $[1,2]$.

Normally, SAPO-34 is prepared from a gel containing sources of an alumina source, a phosphorus source, a silica source, and leastwise one template source by using a hydrothermal method $[3,4]$. The OSDA leads an essential duty in the synthesis of SAPO materials. Therefore, suitable OSDAs perform an indispensable role in the preparation of SAPO-34 involving in structure-directing, charge-compensating, and space-filling. Several organic amine compounds are used as a/an OSDA(s) in SAPO-34 syntheses, for example, tetraethylammonium hydroxide (TEAOH), morpholine (Mor), triethyl amine (TEA), dipropyl amine (DPA), and diethyl amine (DEA) [5-10]. The combination of OSDA surveyed in the preparation of SAPO-34 aims to increase the qualities as well as the catalytic performance of SAPO-34 $[11,12]$. Between these OSDAs, the nanoparticle size of SAPO-34 can be achieved by using the quaternary ammonium compound TEAOH as a template, so TEAOH is the most commonly used compound to synthesize SAPO-34. Reducing the particle size of SAPO-34 enhanced its catalytic behavior in many previous reports. Hirota et al. [13] increased the catalyst lifespan in the methanol-to-olefin reaction by using the SAPO-34 material, which synthesized nanocrystals with particle sizes of $75 \mathrm{~nm}$ compared to that with bigger sizes of $800 \mathrm{~nm}$. Using the sonochemical method with TEAOH as OSDA, Askari et al. [14] also observed $50 \mathrm{~nm}$-sized SAPO-34 nanocrystals, which were active for a long time in the same reaction. However, the high cost of TEAOH limits its industrial applications $[15,16]$. Compared to TEAOH, Mor is much cheaper. However, the use of Mor as an OSDA leads to the creation of materials which have large particle sizes and 
bad catalytic behavior in conversion reactions such as MTO $[7,15]$. When TEAOH and Mor were combined as the binary OSDAs for the synthesis of SAPO-34, the obtained catalyst had a smaller crystal size and a larger surface area, thereby improving the performance of SAPO-34 catalyst in the methanol conversion reaction [17]. A similar behavior was reported by Sedighi et al. [18] who used different combinations of TEAOH and Mor to synthesize SAPO-34 and obtained the catalyst with the most extended lifetime with optimal crystal size and acidity for MTO reaction. TEA is reported to favor the formation of a SAPO-5 impurity phase, although it costs considerably lower compared to TEAOH. However, until now, synthesizing SAPO-34 with a combination of templates containing TEA in the previous reports is relatively rare. Applying combined OSDAs, for instance, adding more than one directing agent into the initial solution to lead the creation of molecular sieve, has demonstrated to be an effective and cost-down method to synthesize SAPO-34 catalysts with nanoparticle size [12].

Furthermore, SAPO-34 with nanoparticle size and higher acid properties also was the most favorite parent zeolite of copper ion-exchanged SAPO-34 catalysts for $\mathrm{NH}_{3}$ SCR of $\mathrm{NO}_{x}$ since their Brønsted acid sites represent a coordinate role with the $\mathrm{Cu}^{2+}$ active sites in this reaction [19]. In SAPO-34, the substitution of aluminum and phosphorus atoms in the neutral aluminophosphate (AlPO34) structural framework by silicon atoms will appear in Brønsted acid sites [2]. Therefore, the interactions between OSDAs and the structure of SAPO materials and the Si content in the initial mixture influence the $\mathrm{Si}$ contribution, resulting in the alteration of the acid properties.

The purpose of this research is the preparation at the optimal TEAOH/Mor/TEA molar ratio of the SAPO-34 material with smaller particle size and high acid properties for further catalytic application in $\mathrm{NH}_{3}$-SCR of $\mathrm{NO}_{x}$ reaction. In this study, the combination of OSDAs between TEA, Mor, and TEAOH was applied to prepare SAPO-34, and the influences of the molar ratio of TEA/Mor/TEAOH on the element composition, morphology, topology, and SAPO-34 zeolite were investigated in detail.

\section{Materials and Methods}

2.1. Synthesis of SAPO-34 Molecular Sieve. SAPO-34 molecular sieves were synthesized via the regular hydrothermal method. The material was prepared from a mixture gel with a molar composition of $1 \quad \mathrm{Al}_{2} \mathrm{O}_{3}: 0.6 \quad \mathrm{SiO}_{2}: 1 \quad \mathrm{P}_{2} \mathrm{O}_{5}: \mathrm{X}$ OSDA(s): $110 \mathrm{H}_{2} \mathrm{O}$, wherein $\mathrm{X}$ is shown in Table 1. Firstly, aluminum isopropoxide (98\%, Merck) was mixed with distilled water, and phosphoric acid ( $85 \%$, aqueous solution, Merck) was added dropwise. The mixture was stirred for one hour until completely dissolved, then tetraethyl orthosilicate TEOS (98\%, Sigma) was added and stirred. After one hour, the templates including morpholine $(99 \% \mathrm{w} / \mathrm{w}, \mathrm{ACS}$ Reagent, Sigma), tetraethylammonium hydroxide $(25 \% \mathrm{w} / \mathrm{w}$, Sigma), and triethylamine (98\%, Merck) were added to the solution. The resulting synthesis gel was further stirred for 6 hours until a uniform reaction mixture was formed and then aged for 12 hours. The obtained gel was crystallized at $200^{\circ} \mathrm{C}$ for
TABLE 1: The composition of OSDAs for SAPO-34 preparation.

\begin{tabular}{lccc}
\hline \multirow{2}{*}{ Name } & \multicolumn{3}{c}{ Organic structure-directing agents $(\mathrm{X})$} \\
& Mor & TEA & TEAOH \\
\hline M1 & - & 3 & - \\
M2 & 3 & - & - \\
M3 & - & - & 3 \\
M4 & 3 & - & 1 \\
M5 & - & 3 & 1 \\
M6 & 3 & 1 & - \\
M7 & 1 & 3 & - \\
M8 & 3 & 3 & 1 \\
\hline
\end{tabular}

48 hours in a Teflon-lined autoclave. The as-synthesized sample was filtered, washed, and then dried at $120^{\circ} \mathrm{C}$ for 6 hours. The obtained sample was heated at $1^{\circ} \mathrm{C} / \mathrm{min}$ and calcinated at $550^{\circ} \mathrm{C}$ for $6 \mathrm{~h}$ to remove the organic compound from template agents.

2.2. Characterization of Samples. The power X-ray diffraction (XRD) data of catalysts were procured by a powder $\mathrm{X}$-ray diffractometer Bruker D8 at room temperature using $\mathrm{Cu}$ anode and $\mathrm{K} \alpha$ radiation at $\lambda=1.54 \AA$ in the angular scale of $5-90^{\circ}$ and scanning mode at $0.02^{\circ}$ per step.

The morphology of the samples was observed by the field emission scanning electron microscope (FE-SEM) on a Hitachi S-4800 (Japan). The chemical composition of the catalysts was determined by the Hitachi system (S-4800 model) scanning electron microscope equipped with a dispersive energy X-ray (EDX) spectrometer.

Fourier-transform infrared (FT-IR) experiments were carried out with a JASCO FT/IR-4600 (Japan) infrared spectroscopy. For the identification of the functional groups or organic compounds in the catalyst, the sample and the $\mathrm{KBr}$ powder were mixed and milled in a mortar, with the component ratio of $\mathrm{KBr}$ and the catalyst at 100:1.

The nitrogen adsorption-desorption isotherms measurements were performed on a Micromeritics 2020 analyzer. Firstly, the as-synthesized catalyst was degassed under vacuum at $300^{\circ} \mathrm{C}$ and then measured at the boiling point of nitrogen $\left(-195^{\circ} \mathrm{C}\right)$. The total surface area was determined based on the Brunauer-Emmett-Teller (BET) theory. The external surface area, micropore surface area, and micropore volume were analyzed by using the t-plot method.

The surface acidity determination was performed on temperature-programmed desorption with ammonia $\left(\mathrm{NH}_{3}-\right.$ TPD) experiments by using the Micromeritics Auto Chem 2920 instrument. In all of the analyses, $0.1 \mathrm{~g}$ of the catalyst sample was placed on a quartz fixed-bed U-shaped microreactor and degased in a continuous-flow nitrogen gas of $50 \mathrm{~mL} / \mathrm{min}$ for 1 hour at $300^{\circ} \mathrm{C}$. The sample was then cooled down to $100^{\circ} \mathrm{C}$ and then exposed to $\mathrm{NH}_{3}$ (helium-ammonia $10 \%)$ for 1 hour and thereafter fluxed with helium air at $100^{\circ} \mathrm{C}$ for 1 hour to remove any physiosorbed ammonia. The progress is continued until a stable baseline is acquired. Then, the $\mathrm{NH}_{3}$-TPD measurements were carried out from $100^{\circ} \mathrm{C}$ to $550^{\circ} \mathrm{C}$ at a fixed heating rate of $10^{\circ} \mathrm{C} / \mathrm{min}$. Finally, the spectrum through desorption of $\mathrm{NH}_{3}$ was recorded. 
The detection of thermal amine compound decomposition of as-synthesized samples was performed by the thermal analysis method by using the thermogravimetric analysis (TGA) and differential scanning calorimeter/thermal analysis (DSC/DTA) instruments (PerkinElmer Pyris-1 TGA and DTA-7) under an airflow of $100 \mathrm{~mL} / \mathrm{min}$ at a heating rate of $20^{\circ} \mathrm{C} / \mathrm{min}$ from room temperature up to $800^{\circ} \mathrm{C}$.

The solid state of ${ }^{29} \mathrm{Si}$ NMR (nuclear magnetic resonance) spectroscopy with MAS (magic-angle spinning) experiments were carried out on a Bruker AV-300 NMR spectrometer (Ettlingen, Germany). To be more specific, the spinning rate was $6 \mathrm{kHz}$ at the magic angle while the recycling rate was $5 \mathrm{~s}$. For the chemical shift, $\mathrm{C}_{6} \mathrm{H}_{15} \mathrm{NaO}_{3} \mathrm{SSi}$ sodium salt (DSS) was used as the reference material.

\section{Results and Discussion}

In the preparation of the SAPO-34 material, the crystallization process depends importantly on the type of organic structure-directing agents because of their interaction with inorganic species and the alkalinity, which have influence on both the nucleation and crystal growth rates.

Figure 1 shows the structure parameters and phase purity of the as-synthesized catalysts prepared by different component ratios of templates through X-ray diffraction spectroscopy. The XRD patterns of all the prepared samples match well with SAPO-34 structures, except for sample M1, which was synthesized with only TEA as a template. That means both single Mor and TEAOH and a mixture with different OSDAs can be used to synthesize SAPO-34. The template TEA was preferable to synthesize SAPO-5 molecular sieves at $2 \theta=7.5,11.1,14.9,19.8,21.1$, and 22.5. The template Mor, TEAOH, or mixture with TEA/Mor/TEAOH was the most appropriate template for SAPO-34 which is characterized by diffraction peaks at $2 \theta=9.6,15.9,19.2,21.7$, and 27.6. In Figure 1, all the as-synthesized samples obtained typical diffraction peaks of the trigonal phase, respectively, for the chabazite structure of SAPO-34 as OSDAs. However, the reflection intensity and the width of peaks were different and depended on the templates. The peaks of the as-synthesized samples with a single template, especially with TEAOH, were sharp and strong, indicating its better crystallinity and phase purity compared to those of the mixed template-prepared samples. The higher intensity and broader width of peaks from the sample prepared with Mor suggest the larger crystallite size of this sample. The least intense reflection of sample M8 indicates a loss of crystallinity and the decrease of crystal size due to the incorporation of Mor with TEAOH and TEA.

Figure 2 illustrates the FE-SEM photographs of synthesized samples prepared by different components of template agents. FE-SEM images clearly show different morphologies and crystal sizes of these samples (as seen in Figure S1, supplementary data). SAPO-5 crystals were obtained when using TEA as a template (M1 sample) which had hexagonal and plate-like morphology, a variation of the particle size from 10-20 $\mu \mathrm{m}$. Using Mor, TEAOH could observe SAPO-34 which had cube-like rhombohedra morphology with different

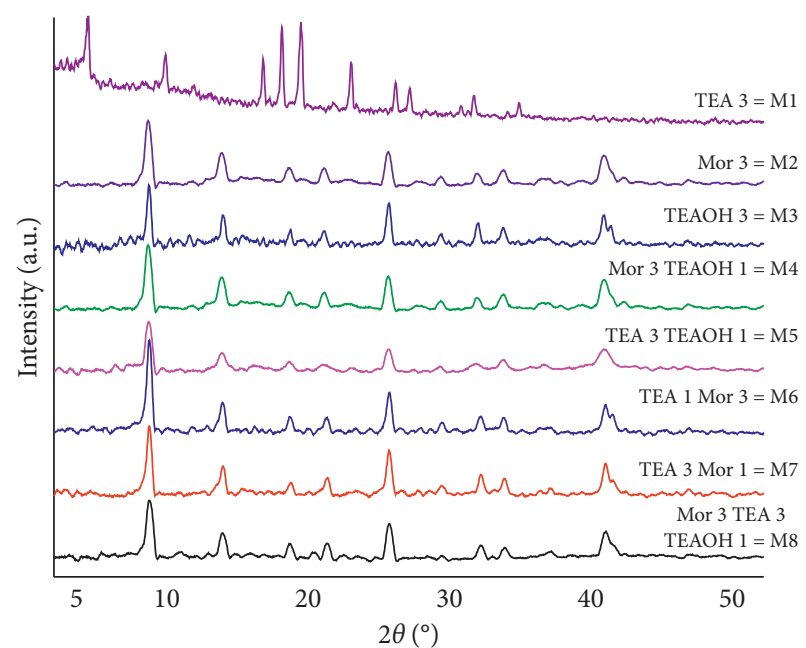

Figure 1: X-ray powder diffraction pattern of the as-synthesized sample.

crystal sizes. M2 and M3 samples obtained perfect crystallization and could be very similar to natural chabazite with, respectively, crystal size varying from $20-45 \mu \mathrm{m}$ and from $3-8 \mu \mathrm{m}$ as well. These results are in agreement with their crystallinity and phase purity from XRD.

A mixture of Mor or TEA with TEAOH has shown the cube-like morphology which is the specific characteristic of SAPO-34 with impurities. FE-SEM photographs of M4 and M5 samples exhibited that SAPO-34 crystallization by TEA/ TEAOH caused the presence of more impurity and larger particles about $5 \mu \mathrm{m}$, whereas using Mor/TEAOH as a templating agent resulted in good material purity with mean crystallite size less than $9 \mu \mathrm{m}$. The use of TEA or TEAOH as a sample in the initial synthetic gel may have a favorable effect in reducing the crystal size. The presence of TEAOH compared to TEA in preparation gel caused significant particle size reduction. Besides, using Mor as a subtemplate probably supports the formation of the purity phase of SAPO-34. The results are in complete agreement with the previous publications $[20,21]$.

The formation of SAPO-34 morphology could be determined by using different kind of templates. M6 and M7 samples have not only same crystallinity which can be seen on XRD pattern but also similar crystal shape of cube-like agglomerating to sphere. This means that TEA and Mor can cause the agglomeration of cubic particles to form a bigger sphere-like particle. The extent of the agglomeration depends on the ratio between templates. The morphology of M6 and M7 suggests that increasing the amount of TEA in the original gel results in the aggregation of cubic crystal into spherical particles. Moreover, combinations of TEA and the other templates lead to the formation of impurity phases [22]. TEAOH template seems to be stronger than morpholine in competition with TEA and directing structure. While the particles synthesized with the mixture of TEAOH and TEA (M5 sample) only contain fewer impurities on the surface but not agglomerated, the crystals of M6 with cubelike morphology appear in competition with the cubic crystals of SAPO-34 including some impurities from the AFI 


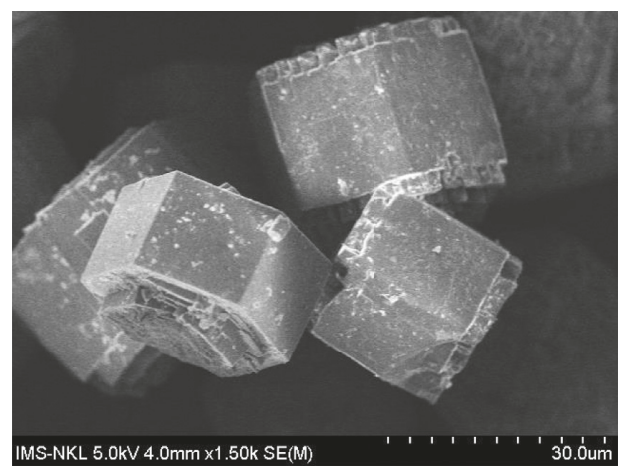

M1

(a)

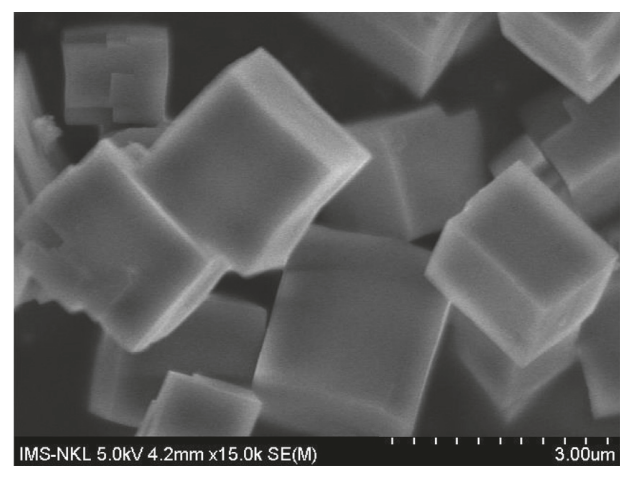

M3

(c)

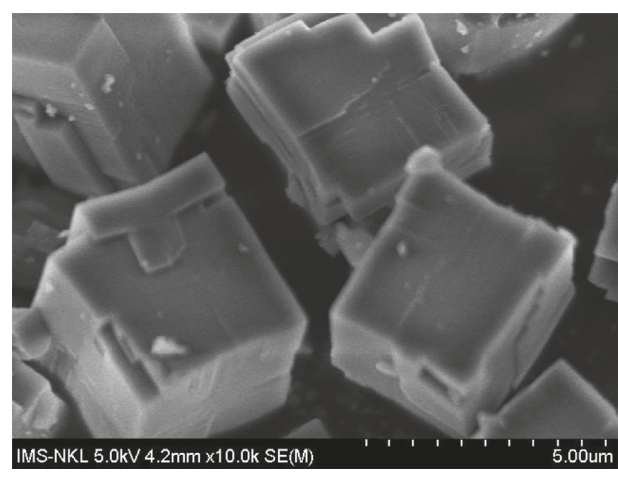

M5

(e)

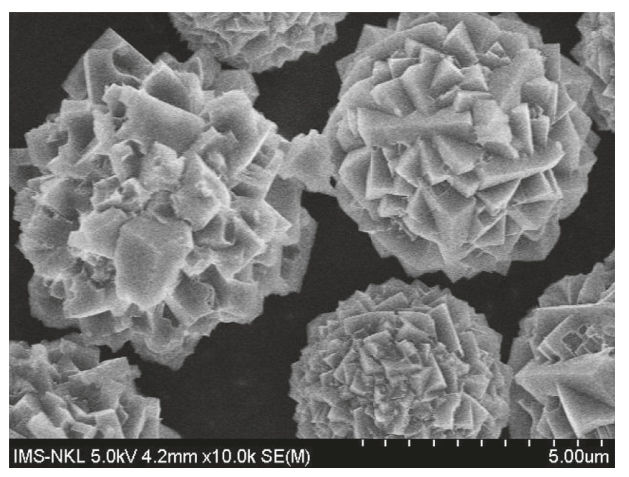

M7

(g)

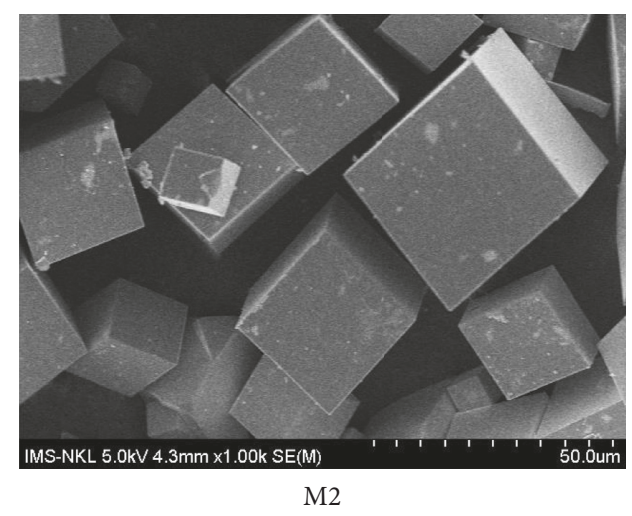

(b)

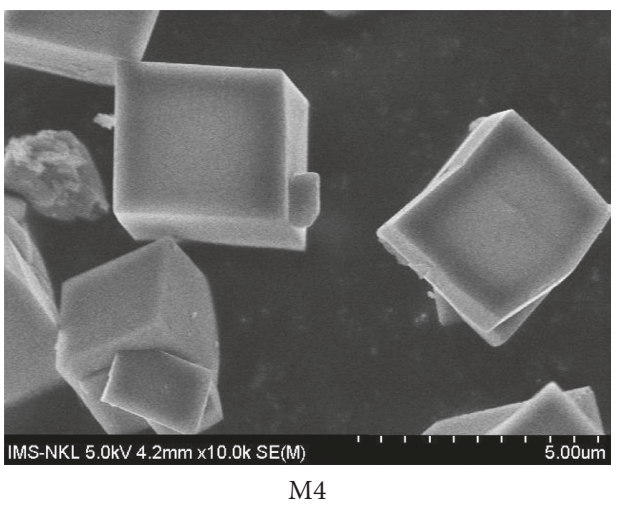

(d)

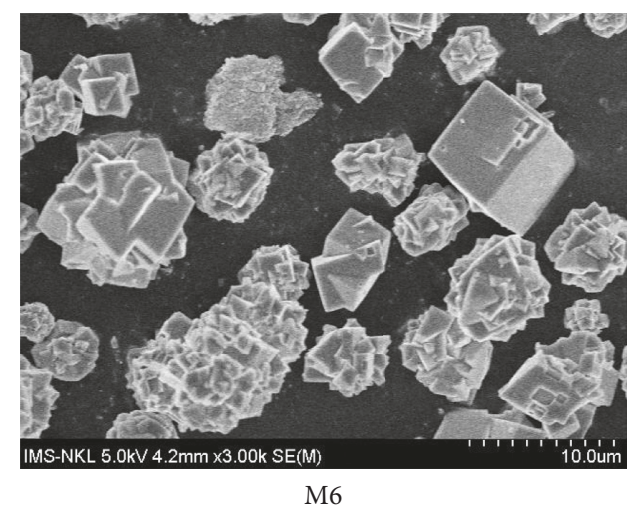

(f)

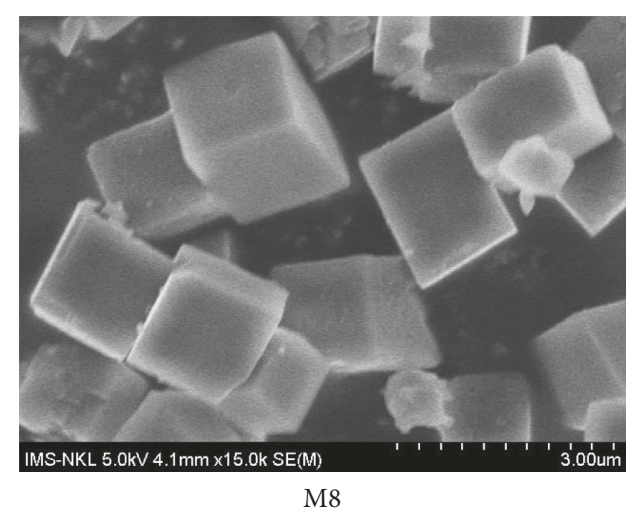

(h)

Figure 2: Field emission scanning electron microscope images of as-synthesized samples. (a) M1. (b) M2. (c) M3. (d) M4. (e) M5. (f) M6. (g) M7. (h) M8. 
structure. Sample M7 synthesized with a higher amount of TEA than that of Mor has a dominant spherical morphology. In the formation of SAPO- 34 catalysts, with the combination of TEA and morpholine, the morphology evolves from spherical agglomerates consisting of micrometer-sized cubic crystals to self-assemblies of spherical nanosheets spliced by nanosquare pieces [23].

Compared to a single and binary template(s), the mixture of tri-templating provides smaller particles of SAPO-34 below $3 \mu \mathrm{m}$. Three templates, including both TEAOH and TEA as agents for monitoring the crystal size, result in a decrease in particle size.

Therefore, nucleation enhancement is probably liable for crystal size reduction [24]. Mixing different OSDAs leads to the reduction in particle size as well as proper arrangement in size distribution and formation of a pure SAPO-34 structure. They can be enhanced by the presence of TEAOH even in little amount. This fact can be explained by the role of structuredirecting substances to fill the space and impact between three different types of OSDA, including TEA, Mor, and TEAOH. Furthermore, using more than one OSDA could narrow space-filling around the molecule templates, leading to a rise in the number of small crystal seeds in the nucleation process.

Table 2 shows the final elemental composition of production evaluated by the EDS analysis. The final SAPO-34 compositions concerning aluminum, silicon, and phosphorous elementals based on $\left(\mathrm{Al}_{X} \mathrm{P}_{Y} \mathrm{Si}_{Z}\right) \mathrm{O}_{2}$ formula were achieved by the mole percentage of each atom. Compared to all starting gel ratio $\mathrm{Si} /(\mathrm{Al}+\mathrm{P}+\mathrm{Si})$ of 0.13 (the $\mathrm{Si}$ content is $13 \%)$, this proportion in products was higher than $13 \%$ after crystallization. The samples synthesized by a single template showed the highest composition of Si element. The composition of $\mathrm{Si}$ element in samples synthesized by a single template was the highest, while that of samples prepared by mixture of OSDAs were lower. This could be attributable to alkaline environment coming from structure-directing agents and the fundamental interactions between templates and structure of SAPO materials. The influence of Si distribution by the number of framework charges are due to not only Si atoms introduced into SAPO-34 channels but also the number of OSDA molecules inserted into cages [25]. It means that if there are an additional content of silicon integrating within the structure of SAPO-34 materials, they could exist as amorphous phase in extra-framework $[15,26]$.

FT-IR spectroscopy is a well-known technique for identifying zeolite materials' framework structures and their acidity due to the appearance of some typical vibrations in IR spectra, which could come from the charge-balancing cations, the framework, or the relatively isolated groups [27]. Figure 3 shows the IR spectra of SAPO-34 with differing OSDA type of the samples, and the transmission bands of the as-synthesized samples are in good agreement with the published data [28-30]. In the fingerprint region $\left(400-1150 \mathrm{~cm}^{-1}\right)$, the bands collected around $500 \mathrm{~cm}^{-1}$ and $620 \mathrm{~cm}^{-1}$ are mainly referred to the T-O tetrahedra bending bands of $\mathrm{SiO}_{4}$ and double- 6 rings. The double- 6 ring is a basic structural unit of $\mathrm{CHA}$ framework; hence, an appearance of this peak corresponds to the successful synthesis of SAPO-34. The vibration band at $850 \mathrm{~cm}^{-1}$ is assigned to the symmetric stretching vibration of
TABLE 2: Elemental compositions and relative crystallinity of the products.

\begin{tabular}{lccc}
\hline Sample name & \multicolumn{3}{c}{ Composition (mol\%) } \\
\hline M2 & \%Al & \% & $\%$ Si \\
M3 & 50.75 & 34.02 & 15.23 \\
M4 & 49.77 & 34.44 & 15.79 \\
M5 & 47.34 & 38.43 & 14.23 \\
M6 & 47.16 & 39.23 & 13.61 \\
M7 & 48.77 & 37.76 & 13.47 \\
M8 & 49.79 & 37.16 & 13.05 \\
\hline
\end{tabular}

$\mathrm{P}-\mathrm{O}$ (or Al-O), while that at $1150 \mathrm{~cm}^{-1}$ is credited for the asymmetric stretching vibration of $\mathrm{O}-\mathrm{P}-\mathrm{O}$. The band at $1600 \mathrm{~cm}^{-1}$ corresponds to the vibrational bending mode of $\mathrm{H}-\mathrm{O}-\mathrm{H}$ weakly adsorbed in the SAPO-34 channels and assigned to $\mathrm{CH}_{3}$ bending vibrational frequencies of the template molecule $[31,32]$. The asymmetric stretching vibration of physically adsorbed $\mathrm{CO}_{2}$ from the environment shows weak absorbance at $2360 \mathrm{~cm}^{-1}$ [27, 28]. All spectra of as-synthesized samples show a broad adsorption band between $3400 \mathrm{~cm}^{-1}$ and $3600 \mathrm{~cm}^{-1}$, which could be allocated to the hydroxyl groups from the $\mathrm{Si}-\mathrm{OH}-\mathrm{Al}$ bond. This hydroxyl bonding evidences that the production of Brønsted acidity of SAPO-34 improves [28]. The intensity of this peak was almost similar for samples M3, M4, M5, and M8, except for M6 sample, which is lower. It could be assumed that the $\mathrm{OH}$ peak in FT-IR spectra of M6 sample is assigned for the formation of hydroxyl groups in the defect structure.

The nitrogen adsorption-desorption isotherms of the assynthesized SAPO-34 samples are displayed in Figure 4, and Table 3 shows the crystal size and surface area of these samples. As seen in Figure 4, M3, M4, M5, and M8 samples displayed the curve at low relative pressures which referred to type I isotherm microporous solids. And, absorption near the saturation pressure in the isotherm lines of the assynthesized samples can be detected due to the intercrystalline porosity, which is common in the nanostructures and microporosity of SAPO-34 [33]. As illustrated in this table, the average sizes of these samples vary from $3 \mu \mathrm{m}$ to $38 \mu \mathrm{m}$ depending on the type of templates. It is significant that the surface area of SAPO- 5 material was smaller than that of the SAPO-34 molecular sieve. The surface area of pure SAPO-34 reached up to $650 \mathrm{~m}^{2} / \mathrm{g}$ in several previous reports [34-36]. Our prepared SAPO-34 samples also have a high surface area in the range from $440 \mathrm{~m}^{2} / \mathrm{g}$ to $725 \mathrm{~m}^{2} / \mathrm{g}$ depending on the type of templates. The highest surface area belonged to the sample prepared by using TEA/TEAOH as OSDAs, which is even higher than that of pure reported SAPO-34. The differences in the surface area are attributable to specific changes in channel dimensions and crystal network caused by each OSDAs.

$\mathrm{NH}_{3}$-TPD descriptions exhibited two desorption profiles of ammonia peaks corresponding to the weak and strong acid sites of as-synthesized SAPO-34 materials (Figure 5). The desorption of $\mathrm{NH}_{3}$ molecules on weak acidic centers, which are mostly Lewis acid sites and/or the Brønsted acid sites produced by either $\mathrm{P}-\mathrm{OH}$ hydroxyl groups not 


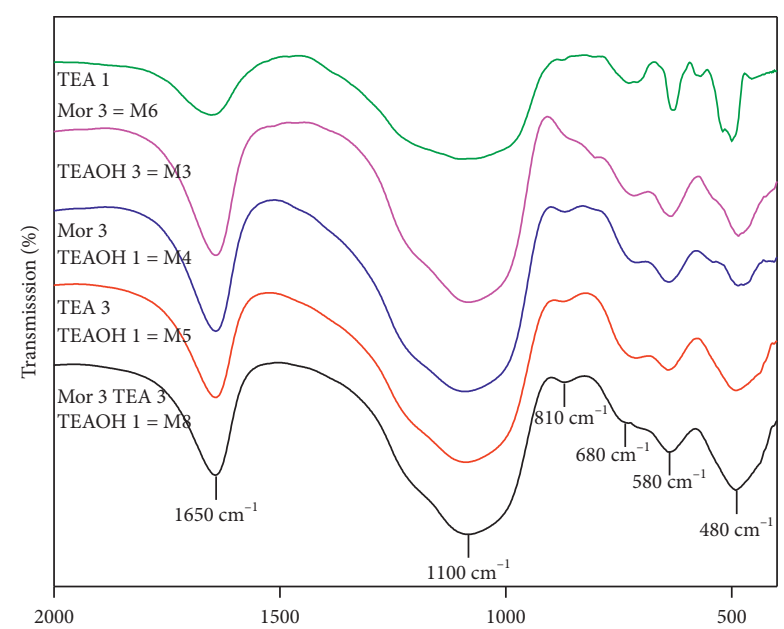

(a)

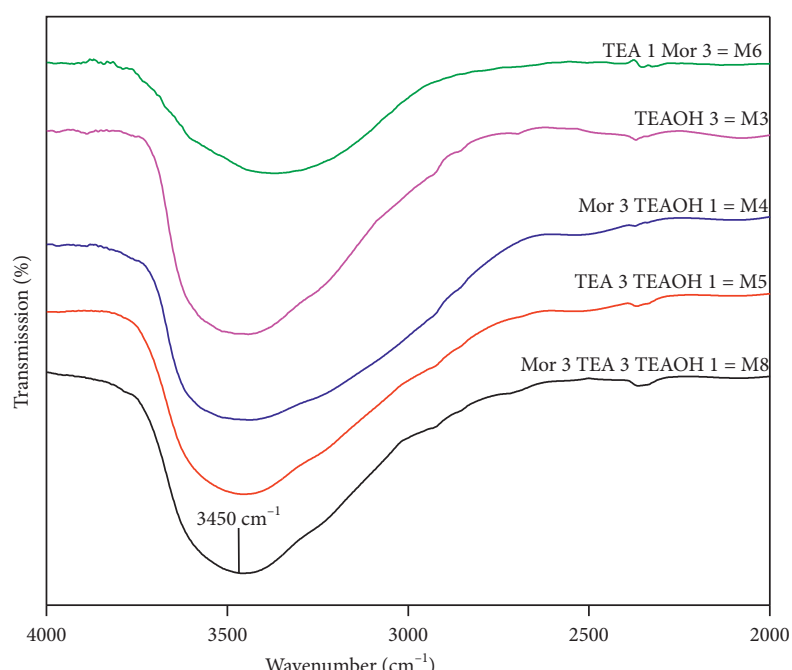

(b)

FIGURE 3: FT-IR spectra of as-synthesized samples with a range of wavelengths: (a) $2000-400 \mathrm{~cm}^{-1}$; (b) $4000-2000 \mathrm{~cm}^{-1}$.

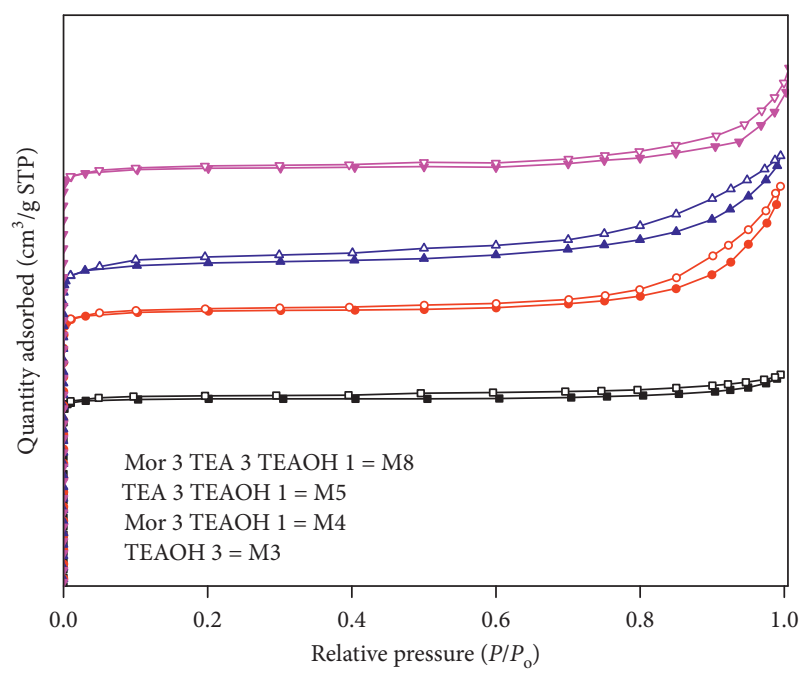

FIGURE 4: $\mathrm{N}_{2}$ adsorption (filled symbols) and desorption isotherms (open symbols) of as-synthesized samples.

TABLE 3: Physicochemical properties of synthesized samples.

\begin{tabular}{lccc}
\hline $\begin{array}{l}\text { Sample } \\
\text { Name }\end{array}$ & $\begin{array}{c}\text { Average } \\
\text { Size }(\mu \mathrm{m})^{\mathrm{a}}\end{array}$ & BET Surface $\left(\mathrm{m}^{2} / \mathrm{g}\right)^{\mathrm{b}}$ & Type of SAPO sample \\
\hline M1 & 16 & 210 & SAPO-5 \\
M2 & 38 & 480 & \\
M3 & 5 & 707 & \\
M4 & 5 & 725 & SAPO-34 \\
M5 & 9 & 683 & \\
M6 & 10 & 440 & \\
M7 & 12 & 466 & \\
M8 & 3 & 697 & \\
\hline
\end{tabular}

${ }^{\mathrm{a}}$ Determined by the FE-SEM image; ${ }^{\mathrm{b}}$ calculated from $\mathrm{N}_{2}$ adsorption data.

sufficiently linked to the $\left[\mathrm{AlO}_{4}\right]$ tetrahedra or $\mathrm{Al}-\mathrm{OH}$ and $\mathrm{Si}-\mathrm{OH}$ groups or other zeolitic defects, causes the appearance of the first peak at a low temperature of $150-250^{\circ} \mathrm{F}$ [37].

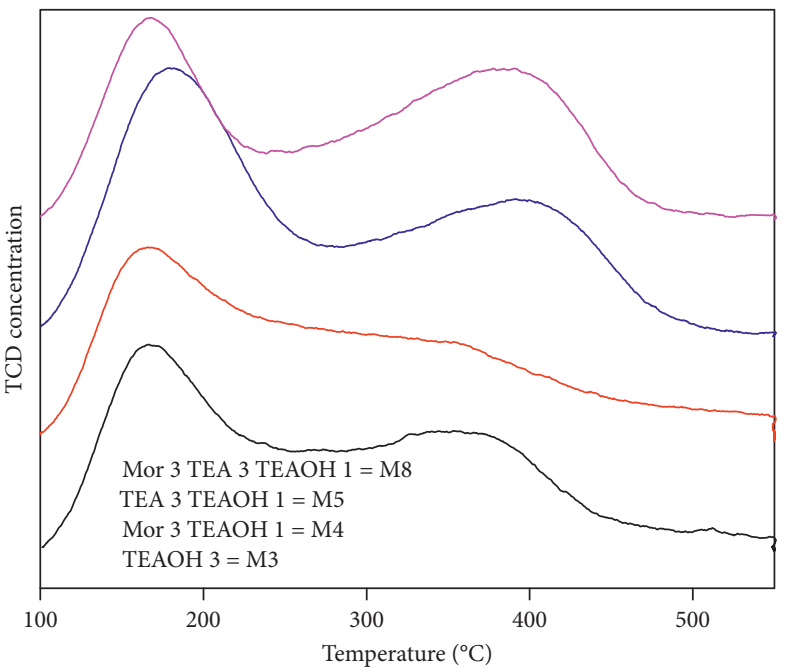

FIGURE 5: $\mathrm{NH}_{3}$-TPD profiles of as-synthesized samples.

The desorption peak shown at a higher temperature of $350-450^{\circ} \mathrm{C}$ is ascribed to the stronger acid sites, formed by the substitution of $\mathrm{P}$ by $\mathrm{Si}$ atoms in the framework of the SAPO-34. These sites are related to Si-OH-Al hydroxyl groups as strong Brønsted acid sites, which should be operated for MTO or deNOx reaction [37, 38].

The amount of $\mathrm{NH}_{3}$ desorption of four samples is different, which depends on the amount of Si contents. The M3 sample with the highest Si content has the highest Brønsted acid sites since these sites ( $\mathrm{Si}-\mathrm{OH}-\mathrm{Al})$ are generated by the proton produced by the template(s) for balancing the negative charges which originated from the incorporation of $\mathrm{Si}$ into the neutral AlPOs framework. The origin of the formation of the acid centers of SAPO-34 molecular sieves is consistent with the previous report [39], in which acid sites were produced by the incorporation of $\mathrm{Si}$ into the aluminophosphate channel. Although Si content of M8 was lower 
than that of the M4 sample (Table 2), the M8 sample exhibited higher total acid sites due to a higher concentration of hydroxyl groups, indicating that the formation of $\mathrm{Si}$ islands in M4 samples might decrease its acid content. Moreover, the combination of TEA/Mor and TEAOH benefits for the $\mathrm{Si}$ incorporation into the SAPO-34 framework, leading to an increase in strong acid amounts of the M8 sample. There is an agreement between the ammoniac adsorption-desorption curve with the FT-IR spectrum of the samples in terms of band region of the $\mathrm{OH}$ vibration. The replacement of $\mathrm{Si}$ for other atoms ( $\mathrm{Si}$ and $\mathrm{P}$ ) in the AlPO framework plays an essential role in acid site production [39].

Figure 6 depicts the TG/DTA curves of the prepared samples under different templating agents burning in the air. Three weight losses (I, II, and III) in the range of $25-800^{\circ} \mathrm{C}$ are observed in the TG analysis. The first weight loss (I) occurring from 25 to $200^{\circ} \mathrm{C}$ is assigned to the desorption progress of physically adsorbed water from the as-synthesized samples. A strongly exothermic process arising between $200^{\circ} \mathrm{C}$ and $450^{\circ} \mathrm{C}$ caused the second weight loss (II) which represented combustion decomposition of the templates. The third weight loss (III) with an exothermic process at a temperature greater than $450^{\circ} \mathrm{C}$ is likely due to the removal of the residual templating agents in the channel molecular sieve of SAPO-34 [40]. The TGA results show that there was a competition among the decomposition of templates at temperatures higher than $500^{\circ} \mathrm{C}$. Three absorption peaks were observed in all differently templating samples. Water decomposition occurred at a low temperature $\left(70^{\circ} \mathrm{C}\right)$ with a weak signal, demonstrating the modest capacity in the molecule and the weak interactions between water molecules and the molecular sieve. The second absorption peak represents the intensity of the removal of the templates. In particular, sample M8, obtained with the tritemplate TEA/Mor/TEAOH, had a sharp and strong removal peak while double-template with several structuredirecting agents, namely, TEA/TEAOH and Mor/TEAOH, had different elevation peaks at this point. The results show that the interaction between the TEAOH agent and the framework of SAPO-34 was the most powerful.

The TGA results of M4, M5, and M8 samples are shown in Table 4. According to the molecular weight loss research, the reduced weight of water was quite small, and the primary reason for weight loss was caused by the removal of the templates. Besides, the weight loss of the different samples was distinct. The moles of templates located in the molecular sieves prepared with the different templates were directly calculated by using the thermogravimetric analysis results. The average number of templating agents per cage in the sample molecular sieve was $1.48,1.25$, and 1.36 with M4, M5, and M8, respectively. For sample M5, which used the dual template of Mor and TEAOH, more favorably entered the cage structure due to the presence of negative charges of morpholine in the SAPO-34 framework. Marchese et al. [41] reported that on average, 1.5 molecules of morpholine present within the chabazite channels of SAPO-34. Meanwhile, the molecular volume of cyclic morpholine is significantly lower than that of TEA, which contains three ethyl

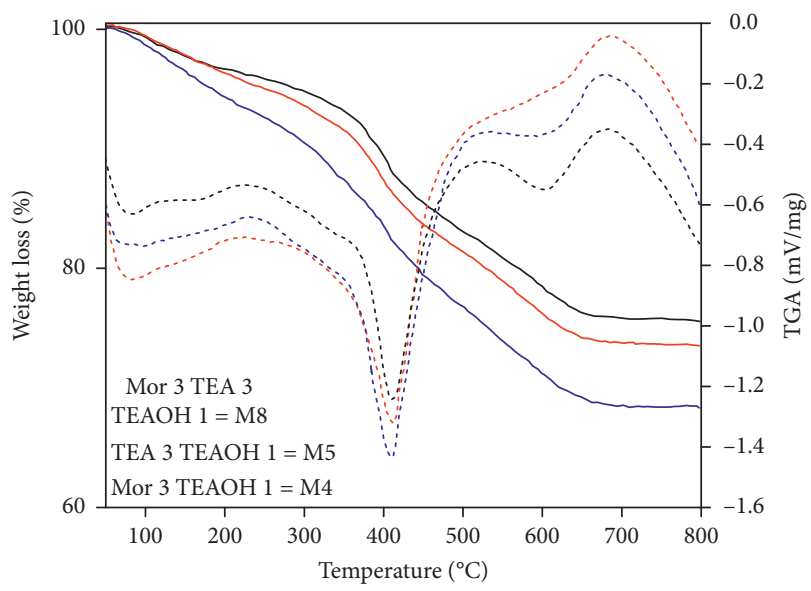

FIgure 6: The TG (straight line) and DTA (dot line) curves for assynthesized samples with different templates.

Table 4: The TGA results for as-synthesized samples.

\begin{tabular}{lccc}
\hline \multirow{2}{*}{ Sample } & \multicolumn{2}{c}{ Weight loss (\%) } & A mole of templates per unit cell \\
& $200^{\circ} \mathrm{C}$ & $200-700^{\circ} \mathrm{C}$ & \\
\hline M4 & 5.62 & 25.815 & 1.48 \\
M5 & 3.64 & 19.91 & 1.25 \\
M8 & 4.33 & 22.62 & 1.36 \\
\hline
\end{tabular}

branches [42]. In the case of Mor/TEA/TEAOH mixture, because the material framework and TEAOH templating agent had the most potent force and easily linked with the aluminum atoms, silicon atoms, and phosphorus atoms at the precursor process of crystallization, adding TEAOH enhances the medium number of OSDAs in the material cage.

The silicon situation in the framework of SAPO-34 was analyzed by ${ }^{29} \mathrm{Si}$ MAS NMR. In Figure 7 , several peaks exhibited in the spectrum of samples M4, M5, and M8 are shown According to [43], the strong peak at $\delta=-90.3 \mathrm{ppm}$ should be due to $\mathrm{Si}(4 \mathrm{Al})$ species; the small peaks formants shown at $\delta=-93.2 \mathrm{ppm}$ and $-98.9 \mathrm{ppm}$ were attributed to $\mathrm{Si}(3 \mathrm{Al})$ and $\mathrm{Si}(2 \mathrm{Al})$ species, respectively, and the peak appeared at $\delta=-108.9 \mathrm{ppm}$ resulting from the $\mathrm{Si}(0 \mathrm{Al})$ environment. The presence of different silicon situations is suitable for the silicone replacement theory [44], in which SM2 (the substitution of $\mathrm{P}$ atoms by $\mathrm{Si}$ atoms alone) and SM3 (a pair Si atoms substituted by a pair of $\mathrm{Al}+\mathrm{P}$ ). A silicon-island region surrounded by the SM2 method was created, and the center was substituted by SM3. Compared to the dual template of Mor/TEAOH and TEA/TEAOH, increasing the relative contents of $\mathrm{Si}(3 \mathrm{Al}), \mathrm{Si}(2 \mathrm{Al}), \mathrm{Si}(1 \mathrm{Al})$, and $\mathrm{Si}(0 \mathrm{Al})$ structures is the result of using a combination of three templates. Based on Table 5 which shows the distribution of the acid properties of as-synthesized catalysts with different template agents, it can be concluded that the creation of silicon islands enhances the acidity of the silicoaluminophosphate zeolite SAPO-34 synonymous with the acid strength of the molecular sieves SAPO-34 which gradually grew up by increasing the size of the silicon islands [45]. The strongest acid sites were located on the borders of the silicon islands. 


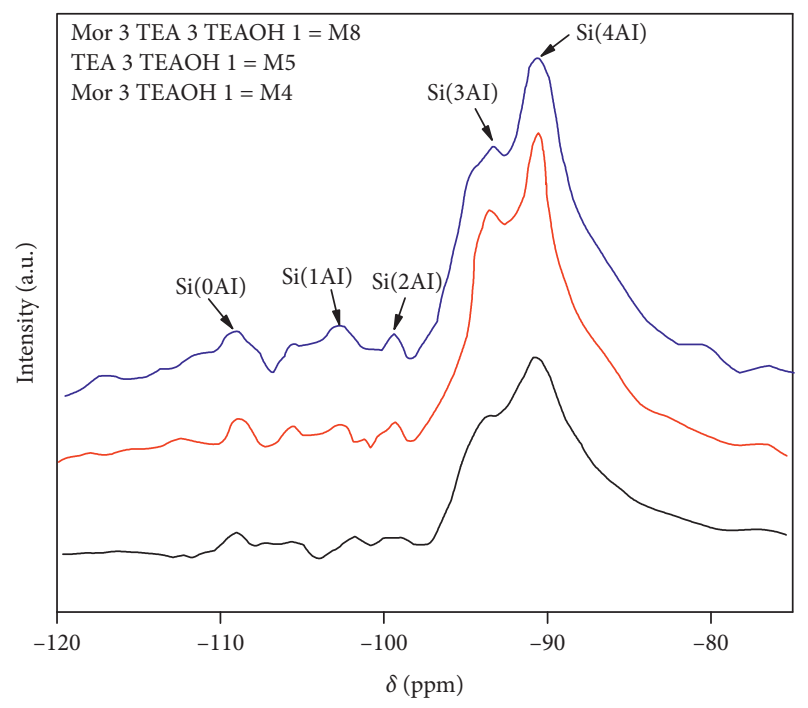

Figure 7: ${ }^{29} \mathrm{Si}$ MAS NMR spectrum of M4, M5, and M8 samples.

TABLe 5: Acid properties of the as-synthesized catalyst.

\begin{tabular}{lccc}
\hline \multirow{2}{*}{ Samples } & \multicolumn{2}{c}{ Peak $(\mathrm{mmol} / \mathrm{g})$} & \multirow{2}{*}{ Total $(\mathrm{mmol} / \mathrm{g})$} \\
& Peak 1 & Peak 2 & 2.25 \\
M3 & 1.34 & 0.91 & 2.05 \\
M4 & 1.15 & 0.90 & 1.95 \\
M5 & 0.99 & 0.96 & 2.34 \\
M8 & 1.25 & 1.19 & \\
\hline
\end{tabular}

\section{Conclusions}

By using the hydrothermal method, SAPO-34 molecular sieves were prepared with various combinations of Mor/ TEA/TEAOH as organic structure-directing agents showed different physicochemical characteristics. The single-template TEA was preferable to synthesize SAPO-5 molecular sieves, while TEAOH and Mor favored SAPO-34 formation. The morphology of all samples was the same to the uniform cube-shaped particles of the standard SAPO-34 material, except as-synthesized samples using Mor/TEA as OSDAs, which additionally includes sphere-shaped particles consisting of cubic agglomerates. Combination of tri-templates in the initial gel led to decrease in the particle size of the samples. The morphology of spherical particles can be created by a coherence of nanosized crystals, and the crystal size will be reduced to submicrometer size. The catalyst with molar ratios of Mor: TEA : TEAOH $=3: 3: 1$ increased the surface area, decreased the crystal size of the samples to nanosize, improved the crystallinity, and enhanced the acid content. The preparation of SAPO-34 catalysts with mixture template synthesis was proven to be effective and has economic advantages.

\section{Data Availability}

The X-ray diffraction, field emission scanning electron microscope, Fourier-transform infrared method, $\mathrm{N}_{2}$ adsorptiondesorption, magic-angle spinning nuclear magnetic resonance, thermogravimetric analysis, differential scanning calorimeter/ thermal analysis, and temperature-programmed desorption of ammonia data used to support the findings of this study are included within the article. The field emission scanning electron microscope data used to support the findings of this study are included within the supplementary information file for more details with images of increased resolution.

\section{Conflicts of Interest}

The authors declare that they have no conflicts of interest.

\section{Acknowledgments}

This work was supported by the RoHan Project funded by the German Academic Exchange Service (DAAD, no. 57315854) and the Federal Ministry for Economic Cooperation and Development (BMZ) inside the framework SDG Bilateral Graduate School Programme. And, this research was also funded by the Vietnam National Foundation for Science and Technology Development (NAFOSTED) under grant no. 104.05-2018.306.

\section{Supplementary Materials}

Supplementary Figure S1. field emission scanning electron microscope images of as-synthesized SAPO-34 from different organic structure-directing agents. FE-SEM images clearly show different morphologies and crystal sizes of these samples on a larger scale. (Supplementary Materials)

\section{References}

[1] B. M. Lok, C. A. Messina, R. L. Patton, R. T. Gajek, T. R. Cannan, and E. M. Flanigen, "Silicoaluminophosphate molecular sieves: another new class of microporous crystalline inorganic solids," Journal of the American Chemical Society, vol. 106, no. 20, pp. 6092-6093, 1984.

[2] M. Zokaie, U. Olsbye, K. P. Lillerud, and O. Swang, "A computational study on heteroatom distribution in zeotype materials," Microporous and Mesoporous Materials, vol. 158, pp. 175-179, 2012.

[3] Z. Yan, B. Chen, and Y. Huang, "A solid-state NMR study of the formation of molecular sieve SAPO-34," Solid State Nuclear Magnetic Resonance, vol. 35, no. 2, pp. 49-60, 2009.

[4] A. T. Aguayo, A. G. Gayubo, R. Vivanco, M. Olazar, and J. Bilbao, "Role of acidity and microporous structure in alternative catalysts for the transformation of methanol into olefins," Applied Catalysis A: General, vol. 283, no. 1-2, pp. 197-207, 2005.

[5] G. Sastre, D. W. Lewis, and C. R. A. Catlow, "Modeling of silicon substitution in SAPO-5 and SAPO-34 molecular sieves," Journal of Physical Chemistry B, vol. 101, no. 27, pp. 5249-5262, 1997.

[6] G. Liu, P. Tian, J. Li, D. Zhang, F. Zhou, and Z. Liu, "Synthesis, characterization and catalytic properties of SAPO-34 synthesized using diethylamine as a template," Microporous and Mesoporous Materials, vol. 111, no. 1-3, pp. 143-149, 2008.

[7] Ø. B. Vistad, D. E. Akporiaye, and K. P. Lillerud, "Identification of a key precursor phase for synthesis of SAPO-34 and kinetics of formation investigated by in situ X-ray diffraction," 
Journal of Physical Chemistry B, vol. 105, no. 50, pp. 1243712447, 2001.

[8] Y. Chen, H. Zhou, J. Zhu et al., "Direct synthesis of a fluidizable SAPO-34 catalyst for a fluidized dimethyl ether-toolefins process," Catalysis Letters, vol. 124, no. 3-4, pp. 297303, 2008.

[9] M. Hunger, M. Seiler, and A. Buchholz, "In situ MAS NMR spectroscopic investigation of the conversion of methanol to olefins on silicoaluminophosphates SAPO-34 and SAPO-18 under continuous flow conditions," Catalysis Letters, vol. 74, pp. 61-68, 2001.

[10] I. M. Dahl, H. Mostad, D. Akporiaye, and R. Wendelbo, "Structural and chemical influences on the MTO reaction: a comparison of chabazite and SAPO-34 as MTO catalysts," Microporous and Mesoporous Materials, vol. 29, no. 1-2, pp. 185-190, 1999.

[11] Y.-J. Lee, S.-C. Baek, and K.-W. Jun, "Methanol conversion on SAPO-34 catalysts prepared by mixed template method," Applied Catalysis A: General, vol. 329, pp. 130-136, 2007.

[12] H.-J. Chae, I.-J. Park, Y.-H. Song et al., "Physicochemical characteristics of SAPO-34 molecular sieves synthesized with mixed templates as MTO catalysts," Journal of Nanoscience and Nanotechnology, vol. 10, no. 1, pp. 195-202, 2010.

[13] Y. Hirota, K. Murata, M. Miyamoto, Y. Egashira, and N. Nishiyama, "Light olefins synthesis from methanol and dimethylether over SAPO-34 nanocrystals," Catalysis Letters, vol. 140, no. 1-2, pp. 22-26, 2010.

[14] S. Askari, R. Halladj, and M. Sohrabi, "Methanol conversion to light olefins over sonochemically prepared SAPO-34 nanocatalyst," Microporous and Mesoporous Materials, vol. 163, pp. 334-342, 2012.

[15] A. M. Prakash and S. Unnikrishnan, "Synthesis of SAPO-34: high silicon incorporation in the presence of morpholine as template," Journal of the Chemical Society, Faraday Transactions, vol. 90, no. 15, pp. 2291-2296, 1994.

[16] L. Ye, F. Cao, W. Ying, D. Fang, and Q. Sun, "Methanol conversion on SAPO-34 catalysts synthesized by tri-templates," MRS Proceedings, vol. 1279, pp. 22-30, 2010.

[17] R. B. Rostami, M. Ghavipour, R. M. Behbahani, and A. Aghajafari, "Improvement of SAPO-34 performance in MTO reaction by utilizing mixed-template catalyst synthesis method," Journal of Natural Gas Science and Engineering, vol. 20, pp. 312-318, 2014.

[18] M. Sedighi, H. Bahrami, and J. Towfighi Darian, "Thorough investigation of varying template combinations on SAPO-34 synthesis, catalytic activity and stability in the methanol conversion to light olefin," RSC Advances, vol. 4, no. 91, pp. 49762-49769, 2014.

[19] J. Ma, Z. Si, X. Wu, D. Weng, and Y. Ma, "Optimizing the crystallinity and acidity of H-SAPO-34 by fluoride for synthesizing $\mathrm{Cu} / \mathrm{SAPO}-34 \mathrm{NH}_{3}$-SCR catalyst," Journal of Environmental Sciences, vol. 41, pp. 244-251, 2016.

[20] N. Nishiyama, M. Kawaguchi, Y. Hirota, D. Van Vu, Y. Egashira, and K. Ueyama, "Size control of SAPO-34 crystals and their catalyst lifetime in the methanol-to-olefin reaction," Applied Catalysis A: General, vol. 362, no. 1-2, pp. 193-199, 2009.

[21] G. Liu, P. Tian, and Z. Liu, "Synthesis of SAPO-34 molecular sieves templated with diethylamine and comparison with other templates," Chinese Journal of Catalysis, vol. 33, pp. 174-182, 2012.

[22] B. Valizadeh, S. Askari, R. Halladj, and A. Haghmoradi, "Effect of synthesis conditions on selective formation of SAPO-5 and SAPO-34," Synthesis and Reactivity in Inorganic,
Metal-Organic, and Nano-Metal Chemistry, vol. 44, no. 1, pp. 79-83, 2014.

[23] J. Zhong, J. Han, Y. Wei et al., "Recent advances of the nanohierarchical SAPO-34 in the methanol-to-olefin (MTO) reaction and other applications," Catalysis Science \& Technology, vol. 7, no. 21, pp. 4905-4923, 2017.

[24] B. Topuz, E. E. Oral, and H. Kalıpçılar, "Low temperature synthesis of SAPO-34 in a recirculating-flow system," Journal of Porous Materials, vol. 20, no. 6, pp. 1491-1500, 2013.

[25] L. Ye, F. Cao, W. Ying, D. Fang, and Q. Sun, "Effect of different TEAOH/DEA combinations on SAPO-34's synthesis and catalytic performance," Journal of Porous Materials, vol. 18, no. 2, pp. 225-232, 2011.

[26] M. Salmasi, S. Fatemi, and A. Taheri Najafabadi, "Improvement of light olefins selectivity and catalyst lifetime in MTO reaction; using $\mathrm{Ni}$ and $\mathrm{Mg}$-modified SAPO-34 synthesized by combination of two templates," Journal of Industrial and Engineering Chemistry, vol. 17, no. 4, pp. 755-761, 2011.

[27] S. M. Auerbach, K. A. Carrado, and P. K. Dutta, Handbook of Zeolites Science and Technology, Marcel Dekker, Inc., New York, NY, USA, 2003.

[28] E. Aghaei and M. Haghighi, "High temperature synthesis of nanostructured Ce-SAPO-34 catalyst used in conversion of methanol to light olefins: effect of temperature on physicochemical properties and catalytic performance," Journal of Porous Materials, vol. 22, no. 1, pp. 187-200, 2015.

[29] S. Tian, S. Ji, D. Lü, B. Bai, and Q. Sun, "Preparation of modified Ce-SAPO-34 catalysts and their catalytic performances of methanol to olefins," Journal of Energy Chemistry, vol. 22, no. 4, pp. 605-609, 2013.

[30] N. Rajić, V. Kaučič, and D. Stojaković, "Synthesis and characterization of the CoSAPO-14 and CoSAPO-34," Zeolites, vol. 10, no. 3, pp. 169-173, 1990.

[31] P. R. H. P. Rao and M. Matsukata, "Dry-gel conversion technique for synthesis of zeolite BEA," Chemical Communications, no. 12, pp. 1441-1442, 1996.

[32] Z. Li, J. Martínez-Triguero, P. Concepción, J. Yu, and A. Corma, "Methanol to olefins: activity and stability of nanosized SAPO-34 molecular sieves and control of selectivity by silicon distribution," Physical Chemistry Chemical Physics, vol. 15, no. 35, pp. 14670-14680, 2013.

[33] Q. Sun, Y. Ma, N. Wang et al., "High performance nanosheetlike silicoaluminophosphate molecular sieves: synthesis, 3D EDT structural analysis and MTO catalytic studies," Journal of Materials Chemistry A, vol. 2, no. 42, pp. 17828-17839, 2014.

[34] J. W. Yoon, S. H. Jhung, Y. H. Kim, S. E. Park, and J. S. Changa, "Selective crystallization of SAPO-5 and SAPO34 molecular sieves in alkaline condition: effect of heating method," Bulletin of the Korean Chemical Society, vol. 26, no. 4, pp. 558-562, 2005.

[35] S. Masoumi, J. Towfighi, A. Mohamadalizadeh, Z. Kooshki, and K. Rahimi, "Tri-templates synthesis of SAPO-34 and its performance in MTO reaction by statistical design of experiments," Applied Catalysis A: General, vol. 493, pp. 103111,2015

[36] C. Kong, J. Zhu, S. Liu, and Y. Wang, "SAPO-34 with a low acidity outer layer by epitaxial growth and its improved MTO performance," RSC Advances, vol. 7, no. 63, pp. 39889-39898, 2017.

[37] B. Parlitz, E. Schreier, H. L. Zubowa et al., "Isomerization of $n$ heptane over Pd-loaded silico-alumino-phosphate molecular sieves," Journal of Catalysis, vol. 155, no. 1, pp. 1-11, 1995.

[38] E. Dumitriu, A. Azzouz, V. Hulea, D. Lutic, and H. Kessler, "Synthesis, characterization and catalytic activity of SAPO-34 
obtained with piperidine as templating agent," Microporous Materials, vol. 10, no. 1-3, pp. 1-12, 1997.

[39] S. Svelle, S. Aravinthan, M. Bjorgen et al., "The methyl halide to hydrocarbon reaction over H-SAPO-34," Journal of $\mathrm{Ca}$ talysis, vol. 241, no. 2, pp. 243-254, 2006.

[40] M. Luo, H. Zang, B. Hu, B. Wang, and G. Mao, "Evolution of confined species and their effects on catalyst deactivation and olefin selectivity in SAPO-34 catalyzed MTO process," RSC Advances, vol. 6, no. 21, pp. 17651-17658, 2016.

[41] L. Marchese, A. Frache, E. Gianotti, G. Martra, M. Causà, and S. Coluccia, "ALPO-34 and SAPO-34 synthesized by using morpholine as templating agent. FTIR and FT-Raman studies of the host-guest and guest-guest interactions within the zeolitic framework," Microporous and Mesoporous Materials, vol. 30, no. 1, pp. 145-153, 1999.

[42] Y. Zhang, Z. Ren, Y. Wang, Y. Deng, and J. Li, "Synthesis of small-sized SAPO-34 crystals with varying template combinations for the conversion of methanol to olefins," Catalysts, vol. 8 , no. 12, p. $570,2018$.

[43] J. Tan, Z. Liu, X. Bao et al., "Crystallization and Si incorporation mechanisms of SAPO-34," Microporous and Mesoporous Materials, vol. 53, no. 1-3, pp. 97-108, 2002.

[44] R. Vomscheid, M. Briend, M. J. Peltre, P. P. Man, and D. Barthomeuf, "The role of the template in directing the Si distribution in SAPO zeolites," Journal of Physical Chemistry, vol. 98, no. 38, pp. 9614-9618, 1994.

[45] G. Sastre, D. W. Lewis, and C. R. A. Catlow, "Modeling of silicon substitution in SAPO-5 and SAPO-34 molecular sieves," Journal of Physical Chemistry B, vol. 101, no. 27, pp. 5249-5262, 1997. 

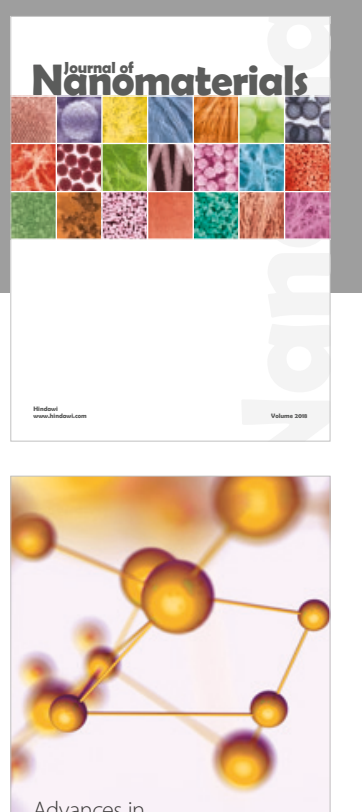

Physical Chemistry
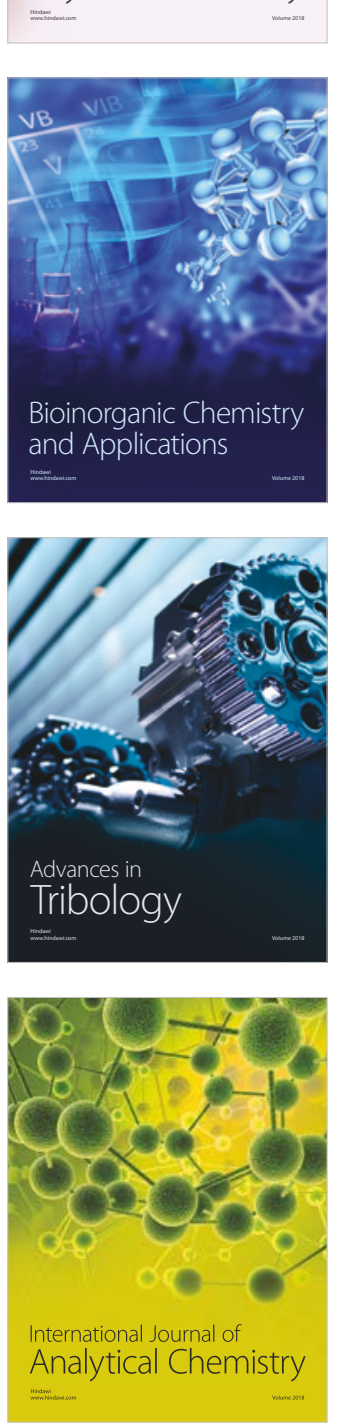

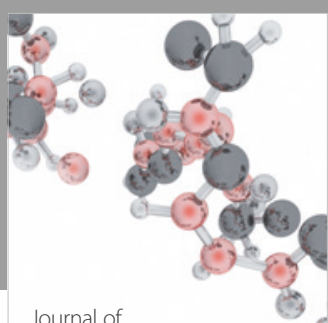

Analytical Methods

in Chemistry

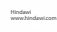

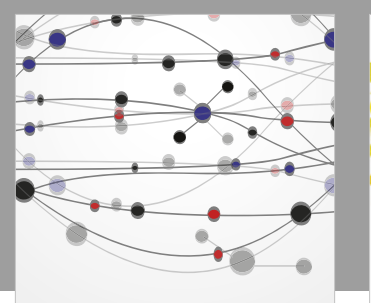

The Scientific World Journal

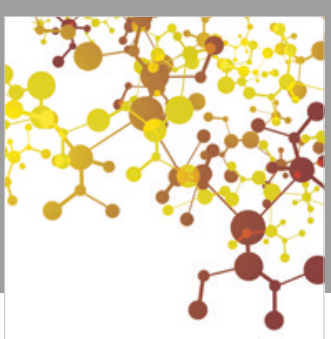

Journal of

Applied Chemistry
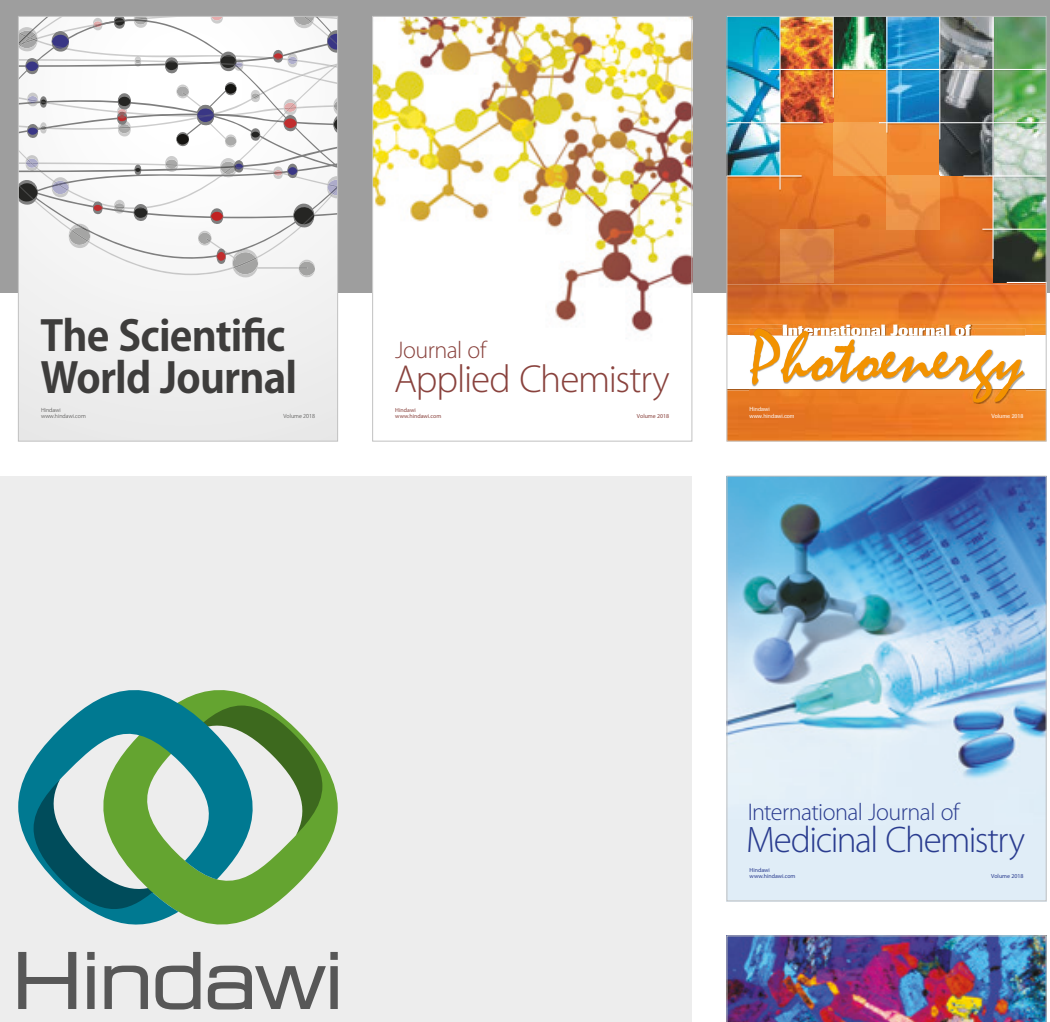

Submit your manuscripts at

www.hindawi.com
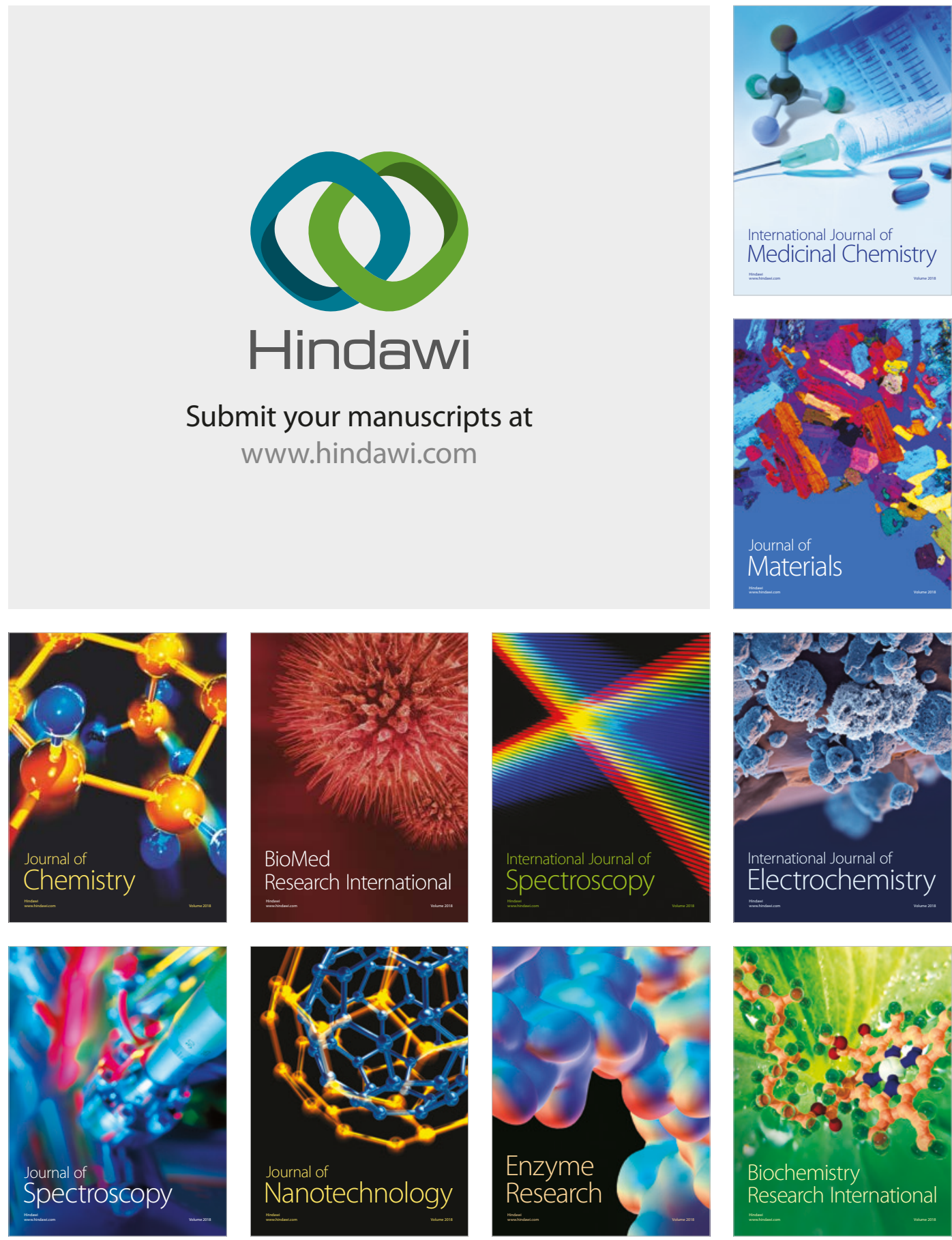
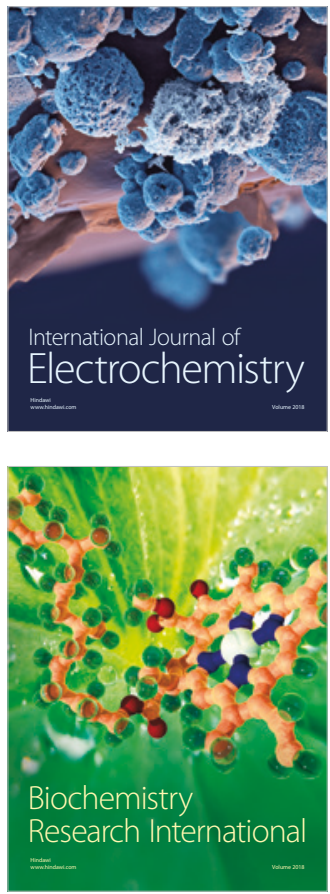